\title{
Development of a Test Method for the Evaluation of DNA Damage in Mouse Spermatogonial Stem Cells
}

\author{
Hye Lyun Jeon ${ }^{1 \dagger}$, Jung-Sun $\mathrm{Yi}^{1 \dagger}$, Tae Sung Kim ${ }^{1}$, Youkyung $\mathrm{Oh}^{1}$, Hye Jeong Lee ${ }^{2}$, Minseong Lee ${ }^{2}$, \\ Jin Seok Bang ${ }^{2}$, Kinarm Ko', II Young Ahn ${ }^{1}$, Kyungyuk Ko', Joohwan Kim', \\ Hye-Kyung Park ${ }^{3}$, Jong Kwon Lee ${ }^{1}$ and Soo Jung Sohn ${ }^{4}$ \\ ${ }^{1}$ Toxicological Screening and Testing Division, National Institute of Food and Drug Safety Evaluation, \\ Ministry of Food and Drug Safety, Osong Health Technology Administration Complex, Cheongju, Korea \\ ${ }^{2}$ Department of Stem Cell Biology, Konkuk University School of Medicine, Seoul, Korea \\ ${ }^{3}$ Toxicological Evaluation and Research Department, National Institute of Food and Drug Safety Evaluation, \\ Ministry of Food and Drug Safety, Osong Health Technology Administration Complex, Cheongju, Korea \\ ${ }^{4}$ Toxicological Research Division, National Institute of Food and Drug Safety Evaluation, \\ Ministry of Food and Drug Safety, Osong Health Technology Administration Complex, Cheongju, Korea
}

(Received January 31, 2017; Revised March 6, 2017; Accepted March 7, 2017)

\begin{abstract}
Although alternative test methods based on the 3Rs (Replacement, Reduction, Refinement) are being developed to replace animal testing in reproductive and developmental toxicology, they are still in an early stage. Consequently, we aimed to develop alternative test methods in male animals using mouse spermatogonial stem cells (mSSCs). Here, we modified the OECD TG 489 and optimized the in vitro comet assay in our previous study. This study aimed to verify the validity of in vitro tests involving mSSCs by comparing their results with those of in vivo tests using C57BL/6 mice by gavage. We selected hydroxyurea (HU), which is known to chemically induce male reproductive toxicity. The $50 \%$ inhibitory concentration $\left(\mathrm{IC}_{50}\right)$ value of $\mathrm{HU}$ was $0.9 \mathrm{mM}$, as determined by the MTT assay. In the in vitro comet assay, \% tail DNA and Olive tail moment (OTM) after HU administration increased significantly, compared to the control. Annexin V, PI staining and TUNEL assays showed that HU caused apoptosis in mSSCs. In order to compare in vitro tests with in vivo tests, the same substances were administered to male C57BL/6 mice. Reproductive toxicity was observed at $25,50,100$, and $200 \mathrm{mg} / \mathrm{kg}$ /day as measured by clinical measures of reduction in sperm motility and testicular weight. The comet assay, DCFH-DA assay, H\&E staining, and TUNEL assay were also performed. The results of the test with C57BL/6 mice were similar to those with mSSCs for HU treatment. Finally, linear regression analysis showed a strong positive correlation between results of in vitro tests and those of in vivo. In conclusion, the present study is the first to demonstrate the effect of HU-induced DNA damage, ROS formation, and apoptosis in mSSCs. Further, the results of the current study suggest that mSSCs could be a useful model to predict male reproductive toxicity.
\end{abstract}

Key words: Alternative test method, Mouse spermatogonial stem cells, Reproductive toxicity, DNA damage, Apoptosis

\footnotetext{
Correspondence to: Jong Kwon Lee, Toxicological Screening and Testing Division, National Institute of Food and Drug Safety Evaluation, Ministry of Food and Drug Safety, Osong Health Technology Administration Complex, 187, Osongsaengmyeong 2-ro, Heungdeok-gu, Osong-eup, Cheongju-si, Chungcheongbuk-do 28159, Korea

E-mail: jkleest@korea.kr

Soo Jung Sohn, Toxicological Research Division, National Institute of Food and Drug Safety Evaluation, Ministry of Food and Drug Safety, Osong Health Technology Administration Complex, 187, Osongsaengmyeong 2-ro, Heungdeok-gu, Osong-eup, Cheongjusi, Chungcheongbuk-do 28159, Korea

E-mail: sjsohn@korea.kr
}

${ }^{t}$ These authors contributed equally to this study.

This is an Open-Access article distributed under the terms of the Creative Commons Attribution Non-Commercial License (http:// creativecommons.org/licenses/by-nc/3.0) which permits unrestricted non-commercial use, distribution, and reproduction in any medium, provided the original work is properly cited. 


\section{INTRODUCTION}

Reproductive and developmental toxicity test methods evaluate toxic effects of substances on reproductive ability and developmental stages including germ cell growth, fertilization, pregnancy, birth and offspring growth. The Organization for Economic Co-Operation and Development (OECD) published Test Guidelines on in vivo reproductive and developmental toxicity test methods. The reproductive and developmental toxicity tests, however, require laboratory animals and costs more than other tests in existing OECD Test Guidelines since the entire reproductive and developmental stages have to be evaluated (1). Therefore, alternative test methods that replace the reproductive and developmental toxicity tests based on the $3 \mathrm{R}$ (Replacement, Reduction, Refinement) principles are required.

Existing reproductive and developmental toxicity tests usually evaluate teratogenesis, abortion, and offspring growth affected by exposure to toxic substances during pregnancy of female animals. However, male animals have been targeted in recent studies to predict reproductive and developmental toxicity $(2,3)$. The European Union Research Laboratory for Alternative in Animal Testing (EURL ECVAM) published the Repair Proficient Comet assay (ReProComet assay) using frozen bovine sperm (ex vivo), computer-assisted sperm analysis (ex vivo), an assay using Leydig cells and Sertoli cells that exist around germ cells as alternative male fertility test methods (4). In vitro tests that directly evaluate sperm toxicity do not exist.

Spermatogonial stem cells (SSCs) are a precursor of germ cells. Mouse SSCs (mSSCs) are less populous $(0.03 \%)$ than the other germ cells in the testis (5). Markers of germ cells (Piwil2, Dazl, Tex18 and Gfral) and pluripotent markers (Oct4 and Sox2) are mainly expressed in mSSCs (6). In vitro $\mathrm{mSSC}$ culture methods have been developed since the 2000 s. In a previous study, in vitro culture of mSSCs isolated from the neonatal testes (DBA/2 background mouse) was conducted (7). mSSCs were then isolated in the adult testes, and adult mouse unipotent mSSCs were converted into pluripotent stem cells $(6,8)$. Recently, studies on mechanism and toxic effects of substances using mSSCs have been performed (9-12).

The comet assay, known as single-cell gel electrophoresis, is a test method to measure DNA damage in individual cells. The comet assay image looks like a 'comet' with a distinct head consisting of intact DNA and a tail, which contains damaged or broken pieces of DNA. This assay is sensitive because it detects low levels of DNA damage (13). It is also a simple method compared with other tests that detect DNA damage (14). The alkaline comet assay is being widely used as a standard test method since it detects DNA damage including single strand breaks, double strand breaks and akali labile site (15). The comet assay has been used widely to evaluate testicular and sperm toxicity including measurement of ROS, antioxidant enzymes and apoptosis (16-21).

Hydroxyurea (HU) is known as a ribonucleotide reductase enzyme that limits DNA biosynthesis by inhibiting the conversion of ribonucleotides into deoxyribonucleotides. HU requires antineoplastic and chemotherapeutic agents $(22,23)$. A previous study showed that HU altered sperm chromatin structure and resulted in abnormal sperm head morphology in mice (24). Another study reported that testis and epididymis weights of transgenic sickle cell mice were reduced after being administered HU (25). HU also decreased sperm density and testosterone concentration (25).

The aim of the present study is to develop a new alternative test method to evaluate reproductive toxicity using mSSCs and identify cytotoxicity mechanisms with HU treatment.

\section{MATERIALS AND METHODS}

Materials. StemPro34 media, StemPro nutrient supplement, N2 supplement, fetal bovine serum (embryonic stem cell qualified, FBS), MEM Vitamin, L-glutamine, D-(+)glucose, pyruvic acid, bovine serum albumin (BSA), minimal essential medium (MEM) non-essential amino acids, MEM sodium pyruvate, $\beta$-mercaptoethanol and Dulbecco's phosphate buffered saline (DPBS) were purchased from Invitrogen (Carlsbad, CA, USA). Penicillin/streptomycin was purchased from Welgene (Daegu, Korea). Recombinant human glial-derived neurotrophic factor (GDNF), recombinant human fibroblast growth factor-basic (bFGF) and recombinant human epidermal growth factor (EGF) were purchased from Peprotech (Rocky Hill, NJ, USA). Recombinant mouse leukemia inhibitory factor (LIF) was purchased from Pospec (East Brunswick, NJ, USA). Matrigel was purchased from Corning Life Science (Corning, NY, USA). Comet slide, lysis solution, and SYBR gold were purchased from Trevigen (Gaithersburg, MD, USA). 2', 7'dichlorodihydrofluorescein diacetate (DCFH-DA) assay kit was purchased from Abcam (Cambridge, UK). Annexin VCy3 apoptosis detection kit, Apo-BrdU-Red in situ DNA fragmentation assay kit and Apo-BrdU-IHC in situ DNA Fragmentation Assay kit were purchased from Biovision (Mountain Veiw, CA, USA). Sperm counting chamber slide was purchased from Leja (Nieuw Vennep, Netherlands). All other materials were purchased from Sigma Chemical Co. (St. Louis, MO, USA) HU was dissolved in culture medium.

Cell culture. mSSCs provided by Dr. Ko (KonKuk University, Seoul, Korea) were used for the experiments. mSSCs were established from Oct4-GFP and Oct4-GFP/LacZ transgenic mice (C57BL/6 background) in the previous studies $(6,8)$. mSSCs were maintained on feeder-free (Matrigel-coated) plates and passaged every five days. Cells were replated $\left(5 \times 10^{5}\right.$ cells/well $)$ in 12 -well plates. $\mathrm{mSSC}$ were cultured 
in StemPro-34 SFM (Grand Island, NY, USA) supplemented with StemPro nutrient supplement, $1 \times \mathrm{N} 2$ supplement, $1 \%$ FBS, $1 \times$ penicillin/streptomycin, $1 \times$ MEM vitamin, $2 \mathrm{mM}$ L-glutamine, $6 \mathrm{mg} / \mathrm{mL} \mathrm{D}$-(+)-glucose, $30 \mathrm{mg} / \mathrm{mL}$ pyruvic acid, $1 \mu \mathrm{L} / \mathrm{mL}$ DL-lactic acid, $5 \mathrm{mg} / \mathrm{mL}$ BSA, $50 \mu \mathrm{M} \beta$ mercaptoethanol, $1 \times$ MEM non-essential amino acids, $30 \mathrm{ng} /$ $\mathrm{mL} \beta$-estradiol, $60 \mathrm{ng} / \mathrm{mL}$ progesterone, $20 \mathrm{ng} / \mathrm{mL}$ EGF, $20 \mathrm{ng} /$ $\mathrm{mL}$ bFGF, $20 \mathrm{ng} / \mathrm{mL}$ GDNF, and $100 \mu \mathrm{g} / \mathrm{mL}$ LIF based on established protocols $(6,26)$. mSSCs were maintained at $37^{\circ} \mathrm{C}$ in a humidified atmosphere containing $5 \% \mathrm{CO}_{2}$.

Cell viability. Cell viability was determined by MTT assay, which measures the reduction in plating efficiency in treatment groups relative to the controls. The cells were seeded in 96-well plates at a density of $8 \times 10^{4}$ cells/well, and incubated in medium in the presence of different concentrations of $\mathrm{HU}$ for $24 \mathrm{~h}$. Cells were also treated with only medium as a vehicle control. Following the incubation period, $10 \mu \mathrm{L}$ of $5 \mathrm{mg} / \mathrm{mL}$ thiazolyl blue tetrazolium bromide (MTT) solution, diluted DPBS were added into each well and the mixture was incubated for a further $3 \mathrm{~h}$ at $37^{\circ} \mathrm{C}$. The medium was aspirated and formazan crystal was dissolved by adding $100 \mu \mathrm{L}$ of isopropanol in to each well. The mixture was incubated at room temperature for $30 \mathrm{~min}$. Thereafter, the absorbance at $570 \mathrm{~nm}$ was measured using an enzyme-linked immunosorbent assay microplate reader (SpectraMax, Molecular Devices, CA, USA). Cell viability was calculated relative to that of the vehicle control. For the determination of $50 \%$ inhibitory concentration $\left(\mathrm{IC}_{50}\right)$ doseresponse graphs were constructed using series of different concentrations of $\mathrm{HU}$.

Measurement of reactive oxygen species (ROS) in mSSCs. To determine intracellular ROS production, DCFHDA assay was conducted using a DCFH-DA assay kit according to the manufacturer's instructions. Cells were seeded in luminometer 96-well plates at a density of $8 \times 10^{4}$ cells/ well, and incubated in medium in the presence of different concentrations of $\mathrm{HU}$ for $24 \mathrm{~h}$. Cells were also treated with only medium as a vehicle control. Here, $25 \mu \mathrm{M}$ DCFH-DA was put into each well and incubated for $45 \mathrm{~min}$ at $37^{\circ} \mathrm{C}$. The cells were then washed with DPBS and $100 \mu \mathrm{L}$ buffer was added into each sample. Intracellular ROS was measure by a Victor 3 fluorescence plate reader (Perkin Elmer, Waltham, MA, USA) at Ex $485 \mathrm{~nm} / \mathrm{Em} 535 \mathrm{~nm}$. ROS values of each sample were divided by cell viability. Finally, relative DCF fluorescence (RFU) was calculated relative to that of the vehicle control.

\section{Analysis of DNA damage of mSSCs by Comet assay.}

Cells were seeded in 24-well plates at a density of $4.5 \times 10^{5}$ cells/well, and incubated in medium in the presence of different concentrations of $\mathrm{HU}$ for $24 \mathrm{~h}$.

The alkaline comet assay performed according to the modified OECD TG 489 protocol (5). Triplicate slides were prepared per treatment. Incubated cells were harvested, centrifuged and gently resuspended in $1 \mathrm{~mL}$ of DPBS. Cells were then centrifuged at $12,000 \mathrm{rpm}$ for $5 \mathrm{~min}$ and the cell pellet was mixed with $180 \mu \mathrm{L}$ of $0.5 \%$ (w/v) low melting agarose and $55 \mu \mathrm{L}$ was immediately pipette onto the comet slide. These slides were refrigerated $\left(4^{\circ} \mathrm{C}\right)$ for more than $20 \mathrm{~min}$. The slides were immersed in $250 \mathrm{~mL}$ chilled lysis solution with $10 \mathrm{mM}$ dithiothreitol (DTT) for $1 \mathrm{~h}$ in a refrigerator. After lysis, the slides were washed twice with distilled water (DW) for $10 \mathrm{~min}$. The slides were then incubated in alkaline buffer ( $0.3 \mathrm{M} \mathrm{NaCl}, 1 \mathrm{mM}$ EDTA) for $20 \mathrm{~min}$ in the dark at $4^{\circ} \mathrm{C}$. Electrophoresis as performed at $21 \mathrm{~V}$ and $300 \mathrm{~mA}$ for $20 \mathrm{~min}$. After that, the slides were washed twice with DW for $5 \mathrm{~min}$. The slides were then immersed for $5 \mathrm{~min}$ in ethanol. Slides were air-dried at room temperature in the dark. Immediately before scoring, slides were stained with $55 \mu \mathrm{L}$ SYBR green $(1: 10,000$ dilution of liquid concentrate). Slides were analyzed using a fluorescence microscope (Leica Microsystems, Wetzlar, Germany) at $40 \times$ magnification. For each sample, 50 comets per slide were analyzed, with three slides scored per sample. The percentage of tail DNA and Olive tail moment (OTM) was measured according to the DNA damage degree using computer software (Komet 5.5, Kinetic Imaging, Liverpool, UK) with a fluorescence microscope (DM-4000B, Leica Microsystems).

Annexin V, PI staining and TUNEL assay. Annexin V measured with Annexin V-Cy3 apoptosis detection kit to examine apoptosis. After treatment of HU for $24 \mathrm{~h}$, cells were washed with DPBS and centrifuged at 1,300 rpm for $5 \mathrm{~min}$. This process was repeated two times. After supernatant was removed, $500 \mu \mathrm{L}$ binding buffer was added. Cells were then stained with $5 \mu \mathrm{L}$ Annexin V-Cy3. The fluorescent intensity of the cells (10,000 events/sample) was measured using FACSCalibur (BD biosciences, Mountain View, CA, USA).

After treatment of $\mathrm{HU}$ for $24 \mathrm{~h}$, cells were washed with DPBS and centrifuged at 1,300 rpm for $5 \mathrm{~min}$. This process was repeated two times. Cells were then stained with $500 \mu \mathrm{L}$ RNase $(0.1 \mathrm{mg} / \mathrm{mL})$ and $500 \mu \mathrm{L}$ PI $(2 \mathrm{mg} / \mathrm{mL})$ for $20 \mathrm{~min}$. The fluorescent intensity of the cells $(10,000$ events/sample) was measured by using FACSCalibur (BD biosciences).

Apoptotic cells were measured by Apo-BrdU-Red in situ DNA fragmentation assay kit. TUNEL assay was based on the ability of terminal deoxynucleotidyl transferase to label the ends of broken double-stranded DNA to detect apoptotic cells with DNA degradation during apoptosis. After $24 \mathrm{~h}$ of HU treatment, cells were washed with DPBS and centrifuged at $300 \times \mathrm{g}$ for $5 \mathrm{~min}$. This process was repeated two times. $1 \mathrm{~mL}$ wash buffer added and cells were centrifuged at $300 \times \mathrm{g}$ for $5 \mathrm{~min}$. After supernatant was removed, $50 \mu \mathrm{L}$ DNA labeling solution was added and cells were 
incubated for $60 \mathrm{~min}$ at $37^{\circ} \mathrm{C}$. After supernatant was removed again, $1 \mathrm{~mL}$ rinse buffer was added and cells were centrifuged at $300 \times \mathrm{g}$ for $5 \mathrm{~min}$. After supernatant was removed, $100 \mu \mathrm{L}$ antibody solution was added and cells were incubated for $30 \mathrm{~min}$ at room temperature. Then, $500 \mu \mathrm{L} 7 \mathrm{AAD} /$ RNase A solution was added and cells were incubated for $30 \mathrm{~min}$ at room temperature. Finally, the fluorescent intensity of the cells $(10,000$ events/sample) was measured by using FACSCalibur (BD biosciences).

Animals. Male C57BL/6 mice (7 weeks old) were obtained from Koatech (Pyeongtaek, Korea). The animals were kept in a Ministry of Food and Drug Administration (Certification Number: 1501MFDS07; Korea) animal facility in accordance with the Association for Assessment and Accreditation of Laboratory Animal Care (AAALAC) International Animal Care Policies (Accredited Unit, KFDA: Unit No. 000996). The animals were given access to a solid diet and sterilized water ad libitum. The mice were housed in a pathogen-free condition at $21 \pm 3^{\circ} \mathrm{C}$, a relative humidity of $55 \pm 15 \%$ and a $12: 12 \mathrm{hr}$ light/dark cycle per day (Lights were on at 08:00 and off at 20:00). The mice were acclimated for a period of one week prior to the commencement of the experiments. The mice showed weight variation of $\pm 20 \%$ of the mean weight and no abnormalities were observed. The mice were randomly allocated to each test group ( 3 mice per group) and the average body weight of each group was similar.

Dose selection, chemical preparation and animal treatment. To assess sperm toxicity in mice, the dose of $\mathrm{HU}(25,50,100$ and $200 \mathrm{mg} / \mathrm{kg} /$ day) was selected on the basis of studies conducted by previous study (25). HU was dissolved in saline solution $(10 \mathrm{~mL} / \mathrm{kg} /$ day $)$ and injected orally (p.o.) in to the mice once a day for two weeks. The animals were weighed daily to adjust the gavage volume.

Body and organ weight. At the end of the two week experimental period, all animals were euthanized by cervical dislocation. The epididymis and testes were quickly removed, the attached tissues were trimmed away, and the organs were weighed. The relative weights of the testis and epididymis were expressed as $\mathrm{mg}$ of tissue/g of body weight.

Sperm motility. After the mouse was sacrificed, epididymis was removed and placed in a $1.5 \mathrm{~mL}$ tube containing $300 \mu \mathrm{L}$ of Hank's balanced salt solution (HBSS) medium containing $0.5 \%$ bovine serum albumin (BSA) at $37^{\circ} \mathrm{C}$. The epididymis was cut into small portions to allow the sperm to swim out. Sperm were incubated for $5 \mathrm{~min}$ at $37^{\circ} \mathrm{C}$. After the incubation, supernatant was taken and was then diluted $1: 1$ to $1: 5$ in HBSS medium containing $0.5 \%$ BSA. Sperm samples $(30 \mu \mathrm{L})$ were placed in Leja counting chambers, and sperm motility was evaluated by using the IVOS sperm
Table 1. Software settings of Tox-IVOS used in the study

\begin{tabular}{lc}
\hline \hline Parameters & Value \\
\hline Chamber type & Leja \\
Temperature of analysis $\left({ }^{\circ} \mathrm{C}\right)$ & 37.0 \\
Frame acquired & 30 \\
Frame rate $(\mathrm{Hz})$ & 60 \\
Minimum static contrast & 15 \\
Minimum cell size (pixels) & 4 \\
Straightness $(\mathrm{STR})$, thresholds $(\%)$ & 50.0 \\
VAP cut-off $(\mu \mathrm{m} / \mathrm{s})$ & 10.0 \\
Progressive minimum VAP $(\mu \mathrm{m} / \mathrm{s})$ & 50.0 \\
VSL cut-off $(\mu \mathrm{m} / \mathrm{s})$ & 0.0 \\
Cell intensity & 75 \\
Magnification & 0.50 \\
\hline
\end{tabular}

analyzer (Hamilton Throne Research, MA, USA). Total sperm motility was measured in the same conditions (Table 1). At least five fields were recorded for each sample analyzed, covering the entire viewable area of the chamber without overlapping successive fields. Sperm motility was calculated relative to that of the vehicle control.

Measurement of reactive oxygen species in mouse sperm. For determining intracellular ROS production, the DCFH-DA assay was conducted using the DCFH-DA assay kit according to the manufacturer's instructions. Intracellular ROS was measured using a Victor 3 fluorescence plate reader (Perkin Elmer) at Ex $485 \mathrm{~nm} / \mathrm{Em} 535 \mathrm{~nm}$. ROS values of each sample divided by sperm counts. Finally, RFU was calculated relative to that of the vehicle control.

Analysis of DNA damage of sperm by Comet assay. The alkaline comet assay performed according to the modified OECD TG 489 protocol. Triplicate slides were prepared per treatment. Sperm sample $(20 \mu \mathrm{L})$ containing $5 \times 10^{5}$ sperm per $\mathrm{mL}$ were suspended in $180 \mu \mathrm{L}$ of $0.5 \%$ (w/v) low melting agarose and $55 \mu \mathrm{L}$ was immediately pipetted onto a comet slide. These slides were incubated for $30 \mathrm{~min}$. The slides were immersed in $250 \mathrm{~mL}$ chilled lysis solution with $10 \mathrm{mM}$ DTT for $1 \mathrm{~h}$ in a refrigerator. After lysis, the slides were washed twice with DW for $10 \mathrm{~min}$. The slides were then incubated in alkaline buffer $(0.3 \mathrm{M} \mathrm{NaCl}, 1 \mathrm{mM}$ EDTA) for $20 \mathrm{~min}$ in the dark at $4^{\circ} \mathrm{C}$. Electrophoresis as performed at $21 \mathrm{~V}$ and $300 \mathrm{~mA}$ for $20 \mathrm{~min}$. After that, the slides were washed twice with DW for $5 \mathrm{~min}$. The slides were then immersed for $5 \mathrm{~min}$ in ethanol. Slides were airdried at room temperature in the dark. Immediately before scoring, slides were stained with $55 \mu \mathrm{L}$ SYBR green ( 1 : 10,000 dilution of liquid concentrate). Slides were analyzed using a fluorescence microscope (DM-4000B, Leica Microsystems) at $40 \times$ magnification. For each sample, 50 comets per slide were analyzed, with three slides scored per sample. The percentage of tail DNA and OTM were measured according to the DNA damage degree using computer 
software (Komet 5.5, Kinetic Imaging Liverpool) with a fluorescence microscope (DM-4000B, Leica Microsystems).

\section{Histopathological observation of testes using H\&E} staining. The testes were fixed overnight in $4 \%$ formaldehyde, dehydrated in ethanol (70, 80, 90, 95 and 100\%) and then embedded in paraffin. Tissue sections $(5 \mu \mathrm{m})$ were mounted onto glass slides and dried at the room temperature for $1 \mathrm{~h}$. Tissue sections were stained with hematoxylin and eosin (H\&E) and then observed under a Nikon Eclipse Ni microscope (Melville, NY, USA).

TUNEL assay. TUNEL assay was performed using an Apo-BrdU-IHC in situ DNA Fragmentation Assay kit. Paraffin-embedded tissue sections were deparaffinized and rehydrated using xylene and ethanol. Tissue sections were stored in $1 \times$ phosphate buffered saline. After permeabilization, endogenous peroxidase was inactivated using hydrogen peroxide. DNA labeling solution was added to tissue sections to stain DNA for 90 min. After that, Anti-BrdU-Biotin antibody added for $90 \mathrm{~min}$ in the dark. Stained tissue sections $(5 \mu \mathrm{m})$ were mounted with mounting solution and then observed under a Nikon Eclipse Ni microscope.

Statistical analyses. Data are expressed as means \pm standard deviation (SD). All statistical analyses were performed using the SPSS 20.0 (Statistical Package for Social Science, SPSS Inc., Chicago, IL, USA) software. Statistical differences in the experimental data were determined using one-way ANOVA followed by two-sided Dunnett's test. A level of $p<0.001$ was used as the criterion for statistical significance.

\section{RESULTS}

Effect of HU on mSSCs' viability, intracellular ROS formation and DNA damage in mSSCs. In order to determine $50 \%$ inhibitory concentration $\left(\mathrm{IC}_{50}\right)$, the MTT assay
(A)

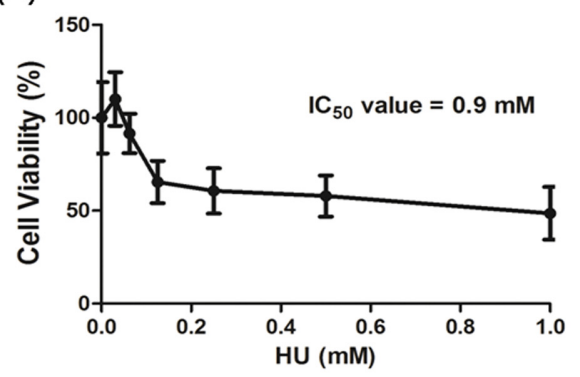

(C)

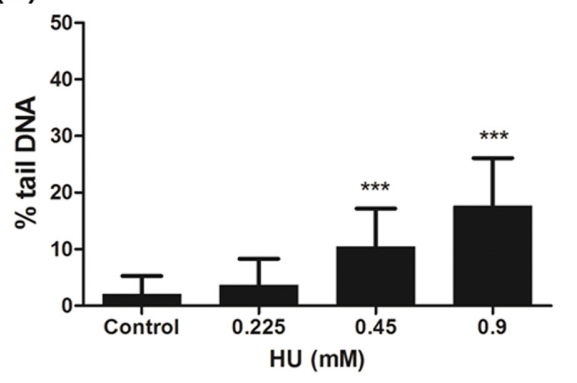

(E)

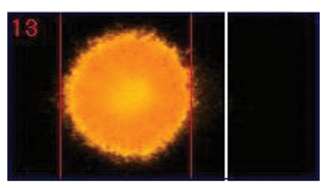

(F)



(B)

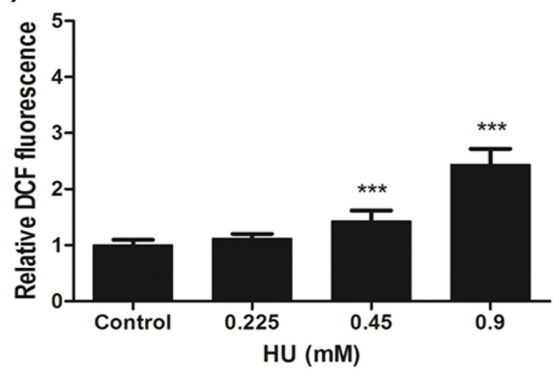

(D)

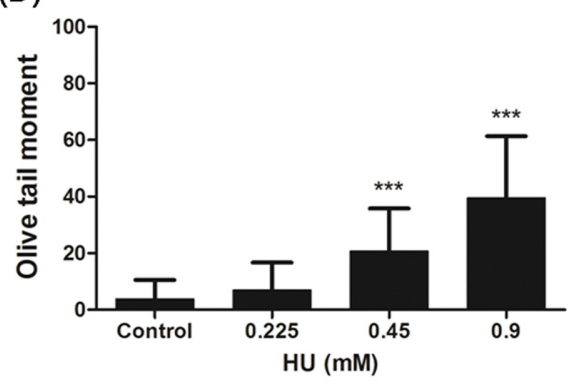

(G)

(H)

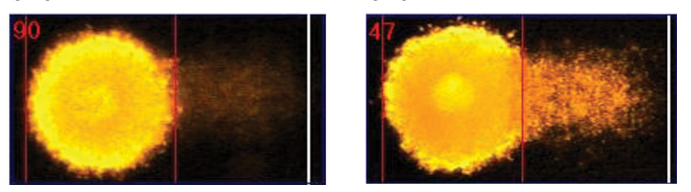

Fig. 1. Effect of HU treatment on Cell viability, ROS formation and Comet parameters (\% tail DNA and OTM) in mSSCs. (A) mSSCs were exposed to various concentrations of $\mathrm{HU}$ for $24 \mathrm{~h}$. Cell viability using MTT assay was expressed as the mean percentage of absorbance values relative to the vehicle control. (B) After mSSCs were treated with 0 0.9 mM HU for $24 \mathrm{~h}$, ROS formation using DCFH-DA assay was measured. Result was expressed as the mean of the DCF fluorescence units relative to the vehicle control. (C) \% tail DNA and (D) OTM were measured by comet assay. Representative photomicrographs of comet assays showing DNA migration pattern in the mSSCs from (E) the control group, $(F) 0.225 \mathrm{mM} \mathrm{HU}$ group, $(\mathrm{G}) 0.45 \mathrm{mM}$ HU group, $(\mathrm{H}) 0.9 \mathrm{mM}$ HU group. All data represent mean \pm SD. ${ }^{* * *} p<0.001$ versus vehicle control. 
conducted. mSSCs were incubated in medium in the presence of different concentrations $(0 \sim 1 \mathrm{mM})$ of $\mathrm{HU}$ for $24 \mathrm{~h}$. As shown in Fig. 1, 0.125 1 mM HU treatment significantly decreased in cell viability $(p<0.001)$. Based on the dose-response curve (Fig. 1A), the $\mathrm{IC}_{50}$ of $\mathrm{HU}$ was deter- mined to $0.9 \mathrm{mM}$.

The production of ROS was determined by DCFH-DA assay. As shown in Fig. 1B, high levels of ROS were significantly produced depending on $0.45 \mathrm{mM}$ and $0.9 \mathrm{mM}$ $\mathrm{HU}$ when compared with the control $(p<0.001)$. Also, HU
(A)
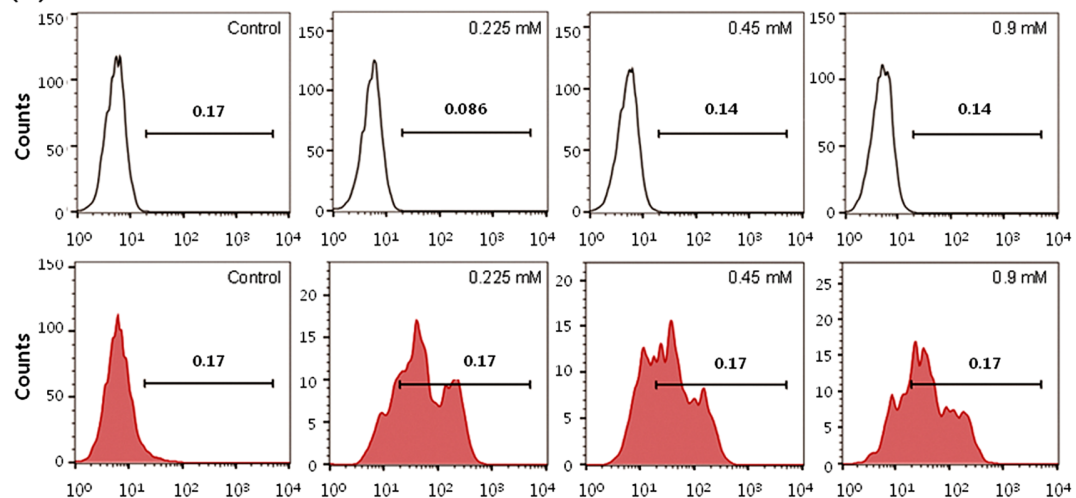

(B)
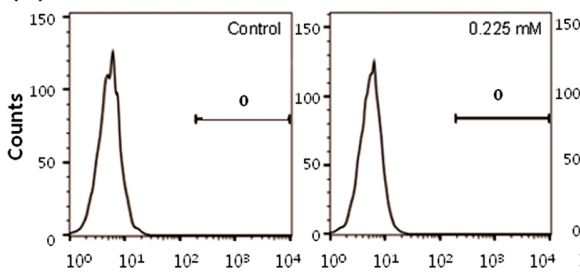

Annexin V


(C)
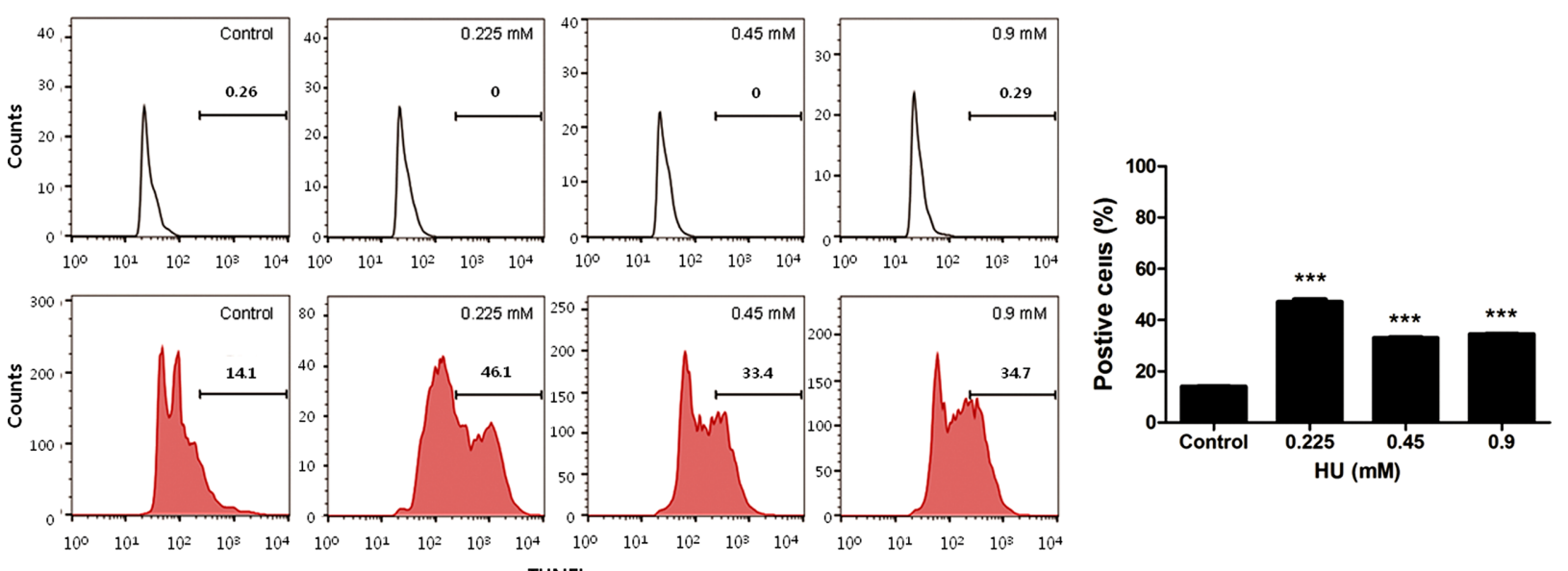

Fig. 2. Effect of $\mathrm{HU}$ on apoptosis in mSSCs. After $\mathrm{HU}(0,0.225,0.45$ and $0.9 \mathrm{mM})$ treatment for $24 \mathrm{~h}$, mSSCs that stained (A) Annexin $\mathrm{V}$, (B) PI and (C) TUNEL were analyzed using FACS. Note upper lines; isotype controls, the broad peak of Annexin-V-Cy3-positive, PI-positive or TUNEL-positive fluorescent cells induced apoptosis. All data represent mean \pm SD. ${ }^{*} p<0.05,{ }^{* *} p<0.01$ or ${ }^{* * *} p<0.001$ versus vehicle control. 
increased intracellular ROS formation in a dose-dependent manner.

To determine the effect of HU on DNA damage in mSSCs, we conducted comet assay using the mSSCs exposed to $0 \sim 0.9 \mathrm{mM}$ HU for $24 \mathrm{~h}$. As shown in Fig. $1 \mathrm{C}$ and $1 \mathrm{D}, \%$ tail DNA and OTM of 0.45 and $0.9 \mathrm{mM}$ HU treatment signifi-

(A)

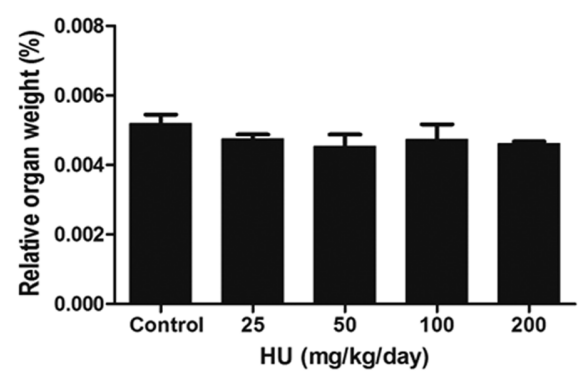

(C)

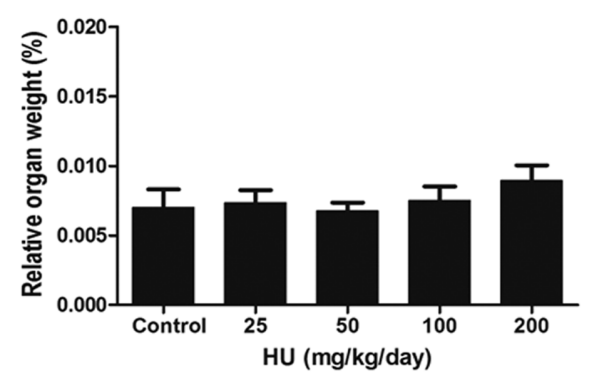

(E)

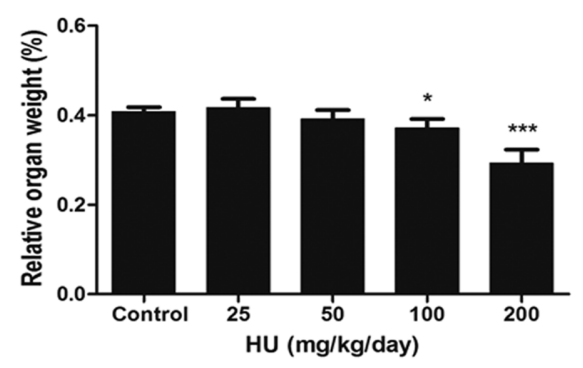

cantly increased in comparison with the control $(p<0.001)$. HU increased comet parameters ( $\%$ tail DNA and OTM) in a dose-dependent manner. Morerover, we observed using photomicrographs that intensity of tail DNA in the mSSCs increased according to HU concentration (Fig. 1E-1H). These results showed HU led to DNA damage in the mSSCs.
(B)

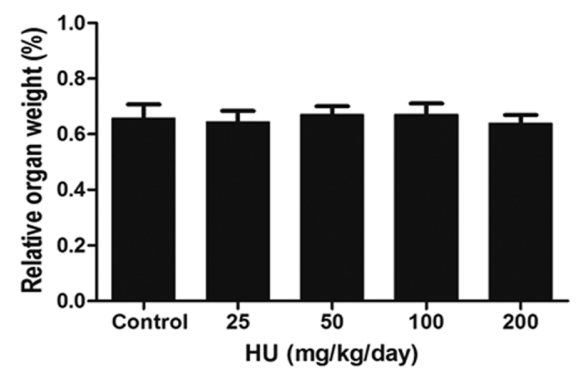

(D)

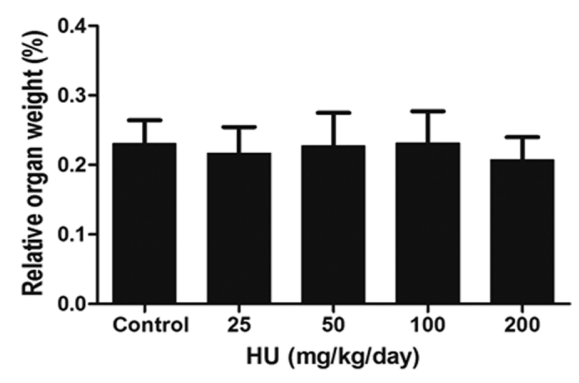

(F)

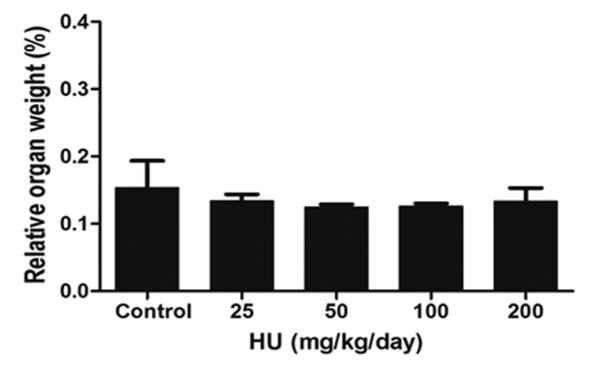

(G)

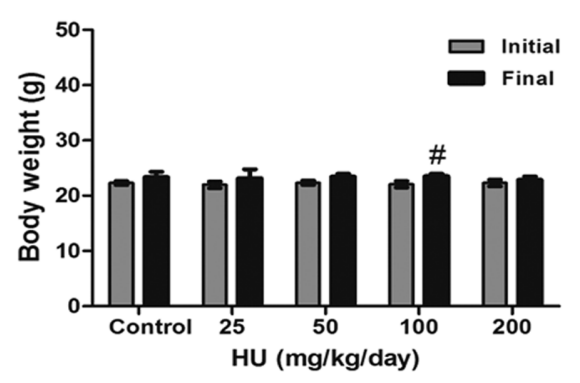

Fig. 3. Effect of $\mathrm{HU}$ on relative organ weights and body weights in C57BL/6 mice. C57BL/6 mice were administered with saline (vehicle control) or $\mathrm{HU}(25,50,100$ and $200 \mathrm{mg} / \mathrm{kg} /$ day) for a period of 14 days. The relative organ weights of the are expressed as mg tissue/g of body weight ((A) liver, (B) kidney, (C) adrenal, (D) spleen, (E) testis and (F) epididymis). (G) Body weights (initial weight and final weight) are expressed. All data represent mean \pm SD. ${ }^{*} p<0.05$ or ${ }^{* * *} p<0.001$ versus vehicle control. ${ }^{*} p<0.05$ versus initial body weights. 
Effect of HU on apoptosis in mSSCs. To examsine the effect of HU on apoptosis in mSSCs, Annexin V, PI staining and TUNEL assay was performed after $0 \sim 0.9 \mathrm{mM} \mathrm{HU}$ treatment in mSSCs for $24 \mathrm{~h}$. As shown in Fig. 2A, AnnexinV-Cy3-positive fluorescent intensity levels of HU-treated mSSCs were significantly increased than that that of control $(p<0.05,0.01$ or 0.001$)$. PI-positive fluorescent cells were significantly increased in mSSCs exposed to all concentration of $\mathrm{HU}(p<0.01$, Fig. 2B). Furthermore, levels of TUNEL-positive fluorescent intensity significantly increased in mSSCs by HU exposure $(p<0.001$, Fig. 2C). These results showed HU induced mSSCs' apoptosis.

Effect of HU on organ and body weight in mice. Liver, kidney, adrenal and spleen weights in HU group were not significantly different compared with those of control (Fig. 3A-3D). Administration of $200 \mathrm{mg} / \mathrm{kg} /$ day $\mathrm{HU}$ to mice resulted in a significant reduction in the relative testicular

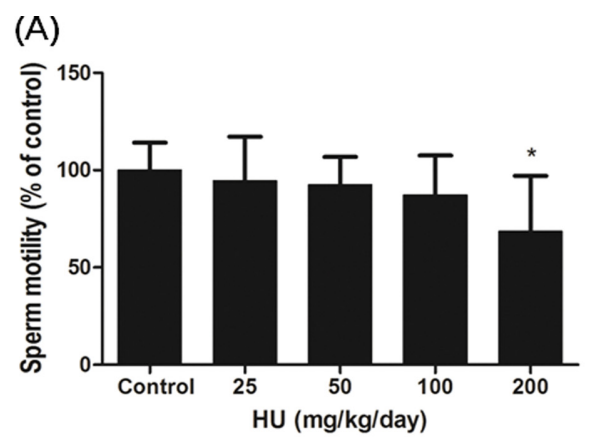

(C)

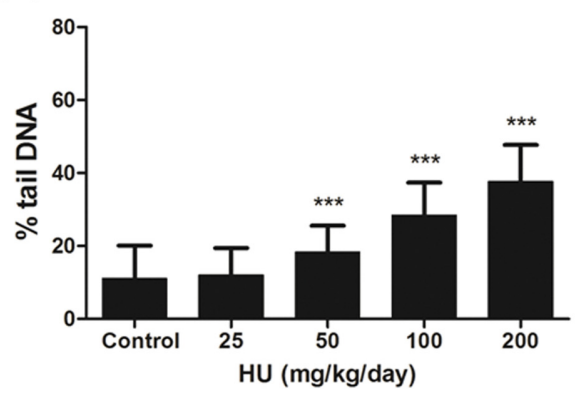

(E)

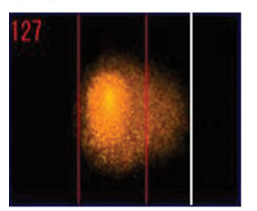

(F)

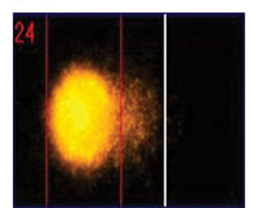

weight $(p<0.001$, Fig. 3E). The final body weights of mice receiving $\mathrm{HU}$ administration were similar to those of control (Fig. 3G). No differences in body weight loss and epididymis weight were found between experimental and control groups (Fig. 3F, 3G).

Effect of HU on motility, intracellular ROS formation and DNA damage in sperm of C57BL/6 mice. The effect of $\mathrm{HU}$ on the sperm motility, a commonly used evaluation of sperm quality, is presented in Fig. 4A. Administration of 200 $\mathrm{mg} / \mathrm{kg} /$ day $\mathrm{HU}$ to mice induced a significant reduction in relative testicular weight $(p<0.001)$. This result showed that the administration of HU led to toxicity in the sperm of mice.

Excessive ROS levels adversely affected to sperm function $(27,28)$. We measured ROS generation in sperm by DCFH-DA assay. Intracellular ROS levels of sperm were significantly increased in $200 \mathrm{mg} / \mathrm{kg} / \mathrm{day} \mathrm{HU}$-administered mice compared with the control group ( $p<0.001$, Fig. 4B).

(B)

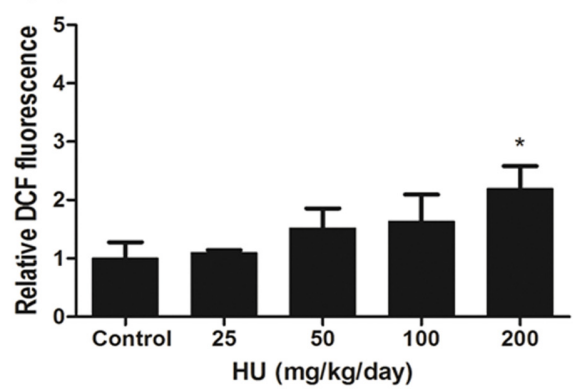

(D)
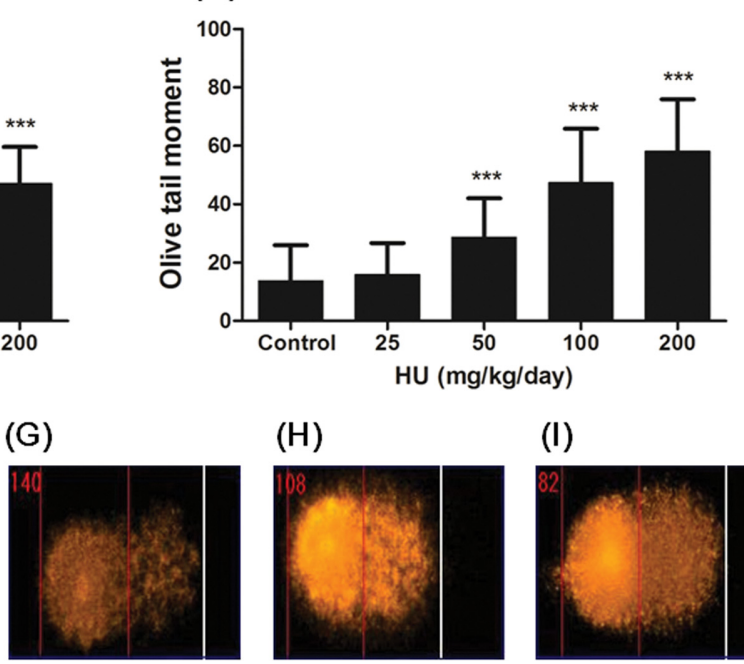

(H)

(I)

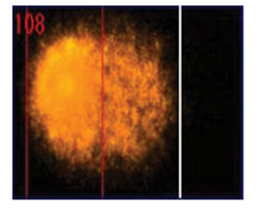

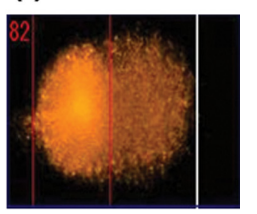

Fig. 4. Effect of HU on motility, ROS formation and DNA damage in sperm. C57BL/6 mice were administered saline (vehicle control) or $\mathrm{HU}(25,50,100$ and $200 \mathrm{mg} / \mathrm{kg} /$ day) for a period of 14 days. (A) Sperm motility values are expressed as the mean percentage relative to the vehicle control. (B) ROS formation using DCFH-DA assay was measured. Results are expressed as mean of the DCF fluorescent units relative to the vehicle control. (C) \% tail DNA and (D) OTM were measured by comet assay. Representative photomicrographs of comet assay showing DNA migration pattern in the sperm of C57BL/6 mice from the (E) control group, (F) $25 \mathrm{mg} / \mathrm{kg} \mathrm{HU} \mathrm{group,} \mathrm{(G)}$ $50 \mathrm{mg} / \mathrm{kg}$ HU group, (H) $100 \mathrm{mg} / \mathrm{kg}$ HU group, (I) $200 \mathrm{mg} / \mathrm{kg}$ HU group. All data represent mean \pm SD. ${ }^{*} p<0.05$ or ${ }^{* *} p<0.001$ versus vehicle control. 
To determine the effect of HU on DNA damage in sperm of C57BL/6 mice, the mice were exposed to $25,50,100$ and $200 \mathrm{mg} / \mathrm{kg} /$ day $\mathrm{HU}$ for 14 days by gavage. As shown in Fig. 4C and 4D, parameters reflecting DNA damage like \% tail DNA and OTM of the HU administration group (50, 100 and $200 \mathrm{mg} / \mathrm{kg} /$ day) were significantly increased in a dose-dependent manner compared with control group $(p<$ 0.001). Also we observed using photomicrographs that intensity of tail DNA in the sperm increased according to HU dose (Fig. 4E-4I). We confirmed that HU caused DNA damage in the sperm.

Effect of $\mathrm{HU}$ on histopathological observation and apoptosis in testes of C57BL/6 mice. H\&E staining is test method to be identify spermatogenesis in the seminiferous tubules of testis. We observed morphological alterations of the testes using H\&E staining before TUNEL assay. The control group showed normal morphology (Fig. 5A). However, the HU administration group showed remarkably reduced numbers of germ cells compared to control.

To investigate the effect of $\mathrm{HU}$ on testicular apoptosis, we performed TUNEL assay in testes following HU administration. We found that the number of testicular apoptotic cells of HU-administered mice increased compared with that of control (Fig. 5B).
Correlation analysis between in vitro and in vivo study. Linear regression analysis between in vitro and in vivo results are presented in Fig. 6. These results showed a strong positive correlation between results of in vitro comet assays (\% tail DNA and OTM) and ROS production using $\mathrm{mSSCs}$ and those of in vivo comet assays using sperm in male $\mathrm{C} 57 \mathrm{BL} / 6$ mice of $\mathrm{HU}\left(\mathrm{R}^{2}=0.96,0.94\right.$, and 0.85 , respectively).

\section{DISCUSSION}

The existing reproductive and developmental toxicity tests require laboratory animals and costs more than other in vivo toxicity tests in the OECD Test Guidelines. Alternative test methods based on the $3 \mathrm{R}$ principles are being developed. However, the development of alternative reproductive toxicity test methods is still at an early stage. Further, a long-term germ cell culture method has not been developed yet. For these reasons, this study was designed to develop an alternative test method using $\mathrm{mSSCs}$ instead of sperm to predict male reproductive toxicity.

In the in vitro comet assay using mSSCs, HU damaged DNA in mSSCs because \% tail DNA and OTM in the HUtreated groups showed a significant increase compared with the control. Further, ROS production of the HU-treated

(A)

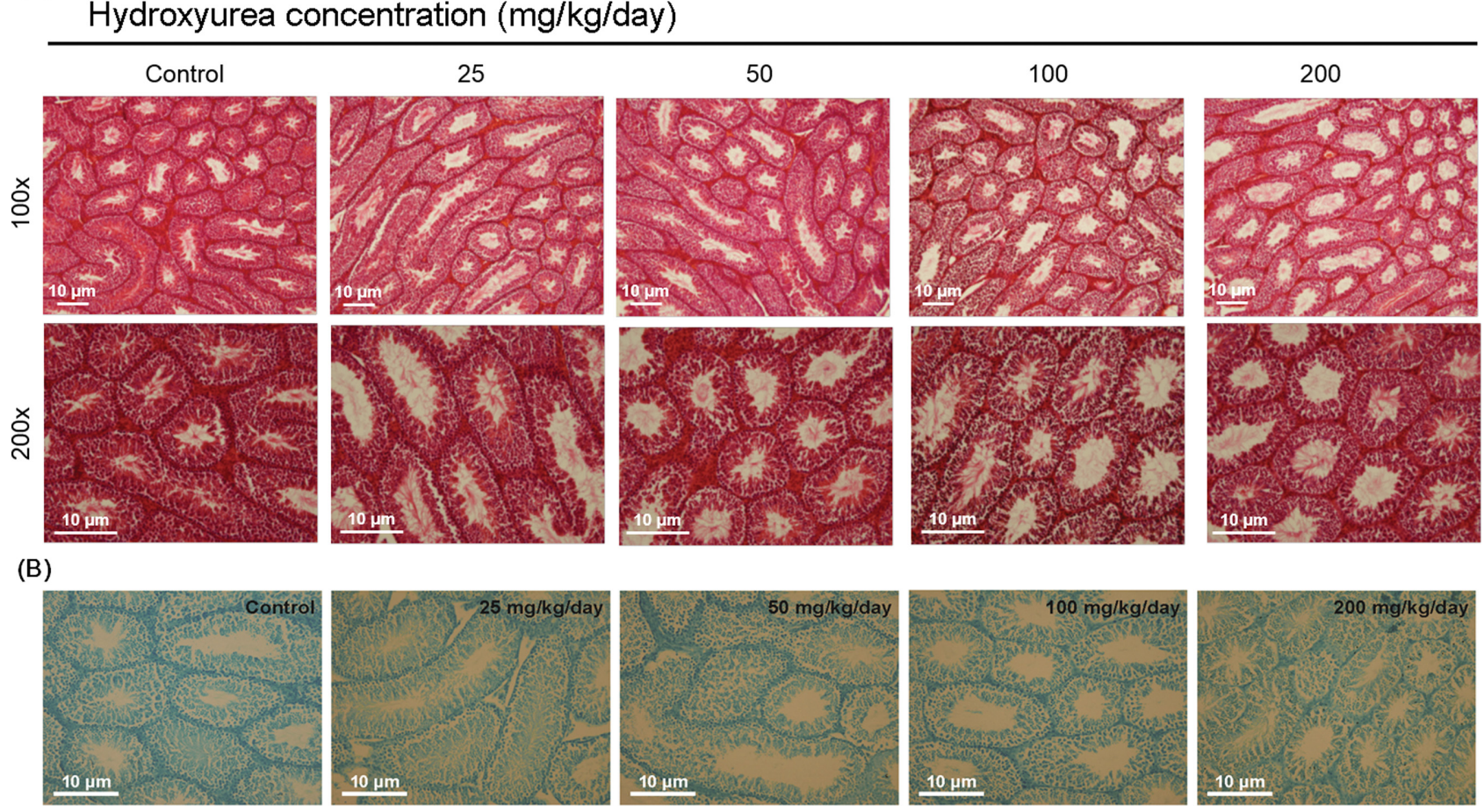

Fig. 5. Effect of $\mathrm{HU}$ on histological changes and apoptosis in testes of C57BL/6 mice. Representative photographs of sperm in testis from male C57BL/6 mice after oral administration of saline (vehicle control) or $\mathrm{HU}(25,50,100$ and $200 \mathrm{mg} / \mathrm{kg} / \mathrm{day})$ for a period of 14 days. (A) Sections were stained with hematoxylin and eosin (Original magnification, 100x, 200x). (B) Sections were stained with TUNEL assay (Original magnification, 200x). 

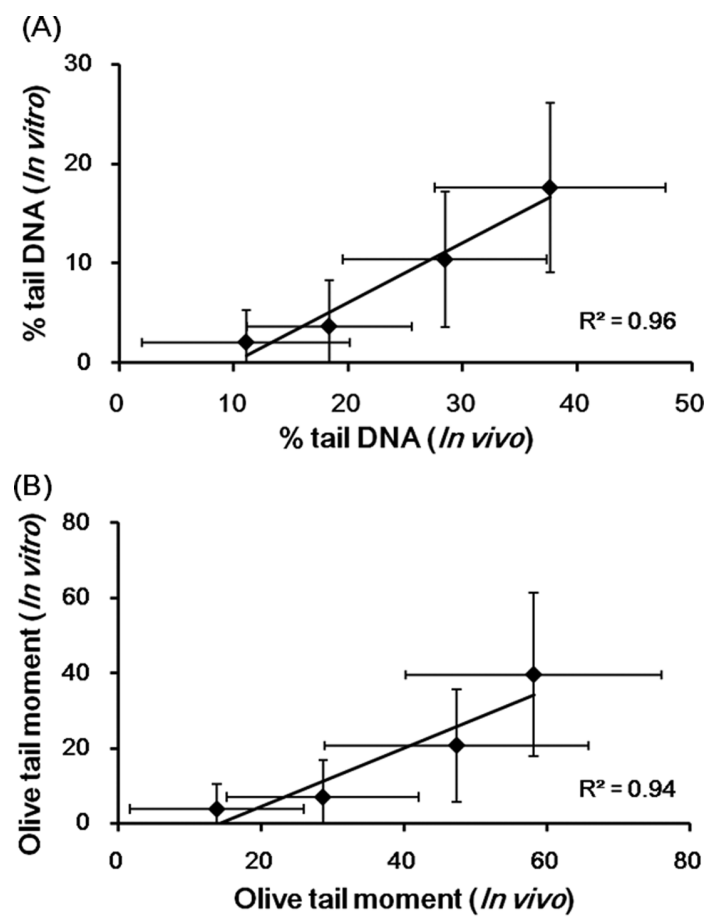

(C)



Fig. 6. Linear regression analysis showed the correlation of in vitro comet assay and in vivo comet assay (A) \% tail DNA, (B) OTM, and (C) ROS production in HU. mSSCs were treated with $\mathrm{HU}(0,0.225,0.45$ and $0.9 \mathrm{mM})$ for $24 \mathrm{~h}$. C57BL/6 mice were administered saline (vehicle control) or $\mathrm{HU}(25,50,100$ and 200 $\mathrm{mg} / \mathrm{kg} /$ day) for a period of 14 days. All the values are expressed as mean $\pm \mathrm{SD}$.

groups grew in a dose-dependent manner in comparison with the control. A previous study reported that HU caused DNA damage through the formation of hydrogen peroxide and nitric oxide (29). Based on this previous study, we believed that HU could cause DNA damage in mSSCs by increasing intracellular ROS production. By measuring apoptosis using the Annexin V, PI staining and TUNEL assay, our current results show values of the HU-treated groups were consistently higher than that of the control. A recent study found out that Toll like receptor 3/interferon regulatory factor 3 facilitated Fas ligand expression and induced apoptosis in spermatogonial stem cells (30). In another study, testicular germ cells of DBA/C57BL mice administered HU significantly increased expression of Fas, Fas ligand, Caspase-3, Caspase- 8 and Caspase- 9 related to apoptosis (31). Consequently, HU-induced apoptosis in mSSCs may be caused by Fas ligand as is the case in germ cells.

In a previous study, lesions similarly occurred in animals treated for two weeks and four weeks. It showed that effects of pharmaceuticals on male reproductive organs could be detected with treatment for two weeks (32). According to another study, it was concluded that treatment for two weeks is enough to evaluate drug-induced effects on male reproductive organs (33). Oral administration of HU for two weeks significantly lowered testicular weight more than the control group. This was similar to a decrease in testicular weights in the groups treated with HU for 28 days and 56 days (25). Moreover, HU administration resulted in significant inhibition of sperm motility and a change in testis morphology. Parameters for DNA damage, such as \% tail DNA and OTM, in the 50, 100 and $200 \mathrm{mg} / \mathrm{kg} /$ day HU administration groups significantly grew in comparison to those with the control mice. HU has been already reported to cause sperm chromatin structure alternation and an increase in abnormal morphology of the sperm head in male C57B/6 J $\times$ $\mathrm{C} 3 \mathrm{H} / \mathrm{HeJ} \mathrm{F}_{1}$ mice (24). Further, a previous study reported that male mice (B6C3/F1/BOM M) showed decreased testicular weight and abnormal sperm chromatin structure on days 27 and 33 after five consecutive days of HU administration (34). HU leads to spermatogenesis delay by changing spermatid stages. A number of previous studies indicated that HU induced reproductive toxicity in male mice. Our data showed that HU caused sperm toxicity as in the previous studies. One of the current means of evaluating male factor infertility, sperm head morphological evaluation test, has a strong positive correlation with the sperm comet assay (35). Thus, our experiment results indicated that the sperm comet assay could evaluate sperm toxicity in HU-administered mice.

ROS balance with anti-oxidants in normal metabolism. However, if imbalanced, the ROS are overproduced and thus, may damage cellular DNA, proteins, and lipids. Sperm are sensitive to ROS because they contain a number of unsaturated fatty acids in the plasma membrane and few antioxidant enzymes in the cytoplasm. An increase in the ROS could damage the sperm membrane and reduce motility and sperm-oocyte fusion. In addition, ROS could be the cause of male infertility because it directly damages sperms' DNA (17). In our study, ROS production significantly increased in the groups receiving $200 \mathrm{mg} / \mathrm{kg} /$ day of $\mathrm{HU}$ compared with the control group.

Apoptosis is the process of programmed cell death that plays a crucial role in development and homeostasis (36). However, if excessive apoptosis occurs, it induces defective spermatogenesis, a decrease in sperm motility, sperm DNA fragmentation, testicular torsion, varicocele and immunolog- 
ical infertility $(37,38)$. Following our TUNEL assay result, we observed that $\mathrm{HU}$ induced apoptotic DNA fragmentations in testes.

Finally, we performed linear regression analysis of the in vitro and in vivo tests. The analysis results demonstrated a strong positive correlation between results of the in vitro tests (\% tail DNA, OTM and ROS production) using mSSCs and those of the in vivo tests using sperm in male C57BL/6 mice of $\mathrm{HU}\left(\mathrm{R}^{2}=0.96,0.94\right.$, and 0.85 , respectively). In conclusion, the present study shows for the first time that HU induces DNA damage, ROS formation and apoptosis in mSSCs. Further, the results of the current study suggest that mSSCs could be a useful model to predict male reproductive toxicity.

\section{ACKNOWLEDGMENTS}

This research was supported by a grant (14181MFDS451) from Ministry of Food and Drug Safety in 2015. We thank Ku Eun-kyung revising the manuscript.

\section{REFERENCES}

1. Rovida, C. and Hartung, T. (2009) Re-evaluation of animal numbers and costs for in vivo tests to accomplish REACH legislation requirements for chemicals - a report by the transatlantic think tank for toxicology (t(4)). ALTEX, 26, 187-208.

2. Schulte, R.T., Ohl, D.A., Sigman, M. and Smith, G.D. (2010) Sperm DNA damage in male infertility: etiologies, assays, and outcomes. J. Assist. Reprod. Genet., 27, 3-12.

3. Makker, K., Agarwal, A. and Sharma, R. (2009) Oxidative stress \& male infertility. Indian J. Med. Res., 129, 357-367.

4. Adler, S., Basketter, D., Creton, S., Pelkonen, O., van Benthem, J., Zuang, V., Andersen, K.E., Angers-Loustau, A., Aptula, A., Bal-Price, A., Benfenati, E., Bernauer, U., Bessems, J., Bois, F.Y., Boobis, A., Brandon, E., Bremer, S., Broschard, T., Casati, S., Coecke, S., Corvi, R., Cronin, M., Daston, G., Dekant, W., Felter, S., Grignard, E., GundertRemy, U., Heinonen, T., Kimber, I., Kleinjans, J., Komulainen, H., Kreiling, R., Kreysa, J., Leite, S.B., Loizou, G., Maxwell, G., Mazzatorta, P., Munn, S., Pfuhler, S., Phrakonkham, P., Piersma, A., Poth, A., Prieto, P., Repetto, G., Rogiers, V., Schoeters, G., Schwarz, M., Serafimova, R., Tähti, H., Testai, E., van Delft, J., van Loveren, H., Vinken, M., Worth, A. and Zaldivar, J.M. (2011) Alternative (non-animal) methods for cosmetics testing: current status and future prospects-2010. Arch. Toxicol., 85, 367-485.

5. Tegelenbosch, R.A. and de Rooij, D.G. (1993) A quantitative study of spermatogonial multiplication and stem cell renewal in the $\mathrm{C} 3 \mathrm{H} / 101 \mathrm{~F} 1$ hybrid mouse. Mutat. Res., 290, 193-200.

6. Ko, K., Arauzo-Bravo, M.J., Kim, J., Stehling, M. and Scholer, R.H. (2010) Conversion of adult mouse unipotent germline stem cells into pluripotent stem cells. Nat. Protoc., 5, 921928.

7. Kanatsu-Shinohara, M., Ogonuki, N., Inoue, K., Miki, H., Ogura, A., Toyokuni, S. and Shinohara, T. (2003) Long-term proliferation in culture and germline transmission of mouse male germline stem cells. Biol. Reprod., 69, 612-616.

8. Ko, K., Tapia, N., Wu, G., Kim, J.B., Arauzo Bravo, M.J., Sasse, P., Glaser, T., Ruau, D., Han, D.W., Greber, B., Hausdorfer, K., Sebastiano, V., Stehling, M., Fleischmann, B.K., Brustle, O., Zenke, M. and Scholer, H.R. (2009) Induction of pluripotency in adult unipotent germline stem cells. Cell Stem Cell, 5, 87-96.

9. Meng, Y.U., Long, W., Yue, H., Zhi-min, L. and Jin-lian, H. (2013) ALK family inhibitor A83-01 promotes the proliferation of mouse male germline stem cells (mGSCs) under serum-and feeder-free conditions. J. Integr. Agric., 12, 18391846.

10. Lei, Z., Qi-sheng, Z., Dong, L., Chao, L., Ahmed, K.E., Beibei, T., Jiu-zhou, S., Ya-ni, Z. and Bi-chun, L. (2015) Study on the role of JAK/STAT signaling pathway during chicken spermatogonial stem cells generation based on RNA-Seq. $J$. Integr. Agric., 14, 939-948.

11. Mahaldashtian, M., Naghdi, M., Ghorbanian, M.T., Makoolati, Z., Movahedin, M. and Mohamadi, S.M. (2016) In vitro effects of date palm (Phoenix dactylifera L.) pollen on colonization of neonate mouse spermatogonial stem cells. J. Ethnopharmacol., 186, 362-368.

12. Hashemi, E., Akhavan, O., Shamsara, M., Daliri, M., Dashtizad, M. and Farmacy, A. (2016) Synthesis and cytogenotoxicity evaluation of graphene on mice spermatogonial stem cells. Colloids Surf. B Biointerfaces, 146, 770-776.

13. Tice, R.R., Agurell, E., Anderson, D., Burlinson, B., Hartmann, A., Kobayashi, H., Miyamae, Y., Rojas, E., Ryu, J.C. and Sasaki, Y.F. (2000) Single cell gel/comet assay: Guidelines for in vitro and in vivo genetic toxicology testing. Environ. Mol. Mutagen., 35, 206-221.

14. Lewis, S.E., John Aitken, R., Conner, S.J., Iuliis, G.D., Evenson, D.P., Henkel, R., Giwercman, A. and Gharagozloo, P. (2013) The imopact of sperm DNA damage in assisted conception and beyond: recent advances in diagnosis and treatment. Reprod. Biomed. Online, 27, 325-327.

15. OECD. (2014) Test No. 489: In vivo Mammalian alkaline Comet assay, OECD Publishing, Paris, pp. 1-25.

16. Mohamed, H.M. and Mohamed, M.A. (2014) Effect of different doses of nandrolone decanoate on lipid peroxidation, DNA fragmentation, sperm abnormality and histopathology of testes of male Wister rats. Exp. Toxicol. Pathol., 67, 1-11.

17. Ceribasi, A.O., Sakin, F., Turk, G., Sonmez, M. and Atessahin, A. (2012) Impact of ellagic acid on adriamycin-induced testicular histopathological lesions, apoptosis, lipid peroxidation and sperm damages. Exp. Toxicol. Pathol., 64, 717-724.

18. La Maestra, S., De Flora, S. and Micale, R.T. (2015) Effect of cigarette smoke on DNA damage, oxidative stress, andmorphological alterations in mouse testis and spermatozoa. Int. J. Hyg. Environ. Health, 218, 117-122.

19. Mojica-Villegas, M.A., Izquierdo-Vega, J.A., Chamorro-Cevallos, G. and Sanchez-Gutierrez, M. (2014) Protective effect of resveratrol on biomarkers of oxidative stress induced by iron/ ascorbate in mouse spermatozoa. Nutrients, 6, 489-503.

20. Khan, S., Ahmad, T., Parekh, C.V., Trivedi, P.P., Kushwaha, S. and Jena, G. (2011) Investigation on sodium valproate induced germ cell damage, oxidative stress and genotoxicity in male Swiss mice. Reprod. Toxicol., 32, 385-394.

21. Rahimipour, M., Talebi, A.R., Anvari, M., Sarcheshmeh, A.A. 
and Omidi, M. (2013) Effects of different doses of ethanol on sperm parameters, chromatin structure and apoptosis in adult mice. Eur. J. Obstet. Gynecol. Reprod. Biol., 170, 423-428.

22. Yarbro, J.W. (1992) Mechanism of action of hydroxyurea. Semin. Oncol., 19, 1-10.

23. Donehower, R.C. (1992) An overview of the clinical experience with hydroxyurea. Semin. Oncol., 19, 11-19.

24. Evenson, D.P. and Jost, L.K. (1993) Hydroxyurea exposure alters mouse testicular kinetics and sperm chromatin structure. Cell Prolif., 26, 147-159.

25. Jones, K.M., Niaz, M.S., Brooks, C.M., Roberson, S.I., Aguinaga, M.P., Hills, E.R., Rice, V.M., Bourne, P., Bruce, D. and Archibong, A.E. (2009) Adverse effects of a clinically relevant dose of hydroxyurea used for the treatment of sickle cell disease on male fertility endpoints. Int. J. Environ. Res. Public Health, 6, 1124-1144.

26. Choi, N.Y., Park, Y.S., Ryu, J.S., Lee, H.J., Arauzo-Bravo, M.J., Ko, K., Han, D.W., Scholer, H.R. and Ko, K. (2014) A novel feeder-free culture system for expansion of mouse spermatogonial stem cells. Mol. Cells, 37, 473-479.

27. Guthrie, H.D. and Welch, G.R. (2012) Effects of reactive oxygen species on sperm function. Theriogenology, 78, 17001708.

28. Sanocka, D. and Kurpisz, M. (2004) Reactive oxygen species and sperm cells. Reprod. Biol. Endocrinol, 2, 12.

29. Sakano, K., Oikawa, S., Hasegawa, K. and Kawanishi, S. (2001) Hydroxyurea induces site-specific DNA damage via formation of hydrogen peroxide and nitric oxide. Jpn. J. Cancer Res., 92, 1166-1174.

30. Hu, J., Song, D., Luo, G., Xu, S., Cao, Y. and Sun, Z. (2015) Activation of Toll like receptor 3 induces spermatogonial stem cell apoptosis. Cell Biochem. Funct., 33, 415-420.
31. Zhou, L., Wu, C.Q., Luo, Y.W., Liao, M.Y. and Sun, Z.Y. (2015) Studies on the characteristics and mechanisms of testicular toxicity induced by Hydroxyurea. Toxicol. Mech. Methods, 25, 396-401.

32. Sakai, T., Takahashi, M., Mitsumori, K., Yasuhara, K., Kawashima, K., Mayahara, H. and Ohno, Y. (2000) Collaborative work to evaluate toxicity on male reproductive organs by repeated dose studies in rats. J. Toxicol. Sci., 25, 1-21.

33. Ozawa, S., Yokoi, R., Kitamura, T., Kuriyama, K., Kobayashi, K. and Shibata, N. (2000) Collaborative work to evaluate toxicity on male reproductive organs by repeated dose studies in rats 15) two-week and 4-week administration study of methyl methanesulfonate (MMS). J. Toxicol. Sci., 25, 155-162.

34. Wiger, R., Hongslo, J.K., Evenson, D.P., De Angelis, P., Schwarze, P.E. and Holme, J.A. (1995) Effects of acetaminophen and hydroxyurea on spermatogenesis and sperm chromatin structure in laboratory mice. Reprod. Toxicol., 9, 21-33.

35. Trivedi, P.P., Kushwaha, S., Tripathi, D.N. and Jena, G.B. (2010) Evaluation of male germ cell toxicity in rats: correlation between sperm head morphology and sperm comet assay. Mutat. Res., 703, 115-121.

36. Steller, H. (1995) Mechanisms and genes of cellular suicide. Science, 267, 1445-1449.

37. Bejarano, I., Espino, J., Paredes, S.D., Ortiz, Á., Lozano, G., Pariente, J.A. and Rodríguez, A.B. (2012) Apoptosis, ROS and calcium signaling in Human Spermatozoa: Relationship to Infertility (Bashamboo, A. Ed.). InTech, Croatia, pp. 51-76.

38. Moline, J.M., Golden, A.L., Bar-Chama, N., Smith, E., Rauch, M.E., Chapin, R.E., Perreault, S.D., Schrader, S.M., Suk, W.A. and Landrigan, P.J. (2000) Exposure to hazardous substances and male reproductive health: a research framework. Environ. Health Perspect., 108, 803-813. 